\title{
Editorial
}

\section{Nano/Molecular Photosciences and Clean Energy}

\author{
Mohamed Sabry Abdel-Mottaleb ${ }^{1}$ and Jean-Marie Herrmann ${ }^{2}$ \\ ${ }^{1}$ Department of Chemistry, Faculty of Science, Ain Shams University, Abbassia, Cairo 11566, Egypt \\ ${ }^{2}$ IRCELYON, CNRS-Université Lyon-1, 69626 Villeurbanne, France
}

Correspondence should be addressed to Mohamed Sabry Abdel-Mottaleb, phochem08@photoenergy.org

Received 25 December 2008; Accepted 25 December 2008

Copyright (C) 2008 M. S. Abdel-Mottaleb and J.-M. Herrmann. This is an open access article distributed under the Creative Commons Attribution License, which permits unrestricted use, distribution, and reproduction in any medium, provided the original work is properly cited.

This special issue on "nano/molecular photosciences and clean energy" is composed of selected, full-length versions of papers presented at the International Conference on Nano/Molecular Photochemistry, Photocatalysis and Solar Energy Conversion (Solar '08). The highly successful solar conference series, started in 1991, provide a place where researchers interested in fundamental and applied aspects of photochemistry can meet and inspire one another. The solar conference recognizes that successful photochemical applications go hand in hand with advancement of fundamental understanding of photoinduced processes and excited states.

This conference was held in Cairo, Egypt, during the period 24-28 February, 2008. It was aimed at discussing in an interdisciplinary sense the newest trends, break-through, discoveries, and applications in photochemistry, photocatalysis, solar energy conversion, environmental aspects, and related nanoscience and nanotechnology.

This conference, as the previous ones, enjoyed high esteem, due to high scientific level and excellent organizational features. There were more than 200 participants from 36 countries world-wide: Algeria, Australia, Canada, China, Czech Republic, Egypt, France, Georgia, Germany, Greece, Hungary, India, Iran, Ireland, Italy, Japan, Kenya, Korea, Libya, Lithuania, Malaysia, Norway, Poland, Portugal, Romania, Russia, Saudi Arabia, Singapore, South Africa, Spain, Sweden, Switzerland, Taiwan, the Netherlands, UK, and USA. The conference was not the "monolith" on narrow subject matter. Rather the other way round: there was a great diversity of topics: organic and inorganic chemistry, basic science, $\mathrm{R} \& \mathrm{D}$, and industrial topics. The main motif was to demonstrate the use of light energy, especially sunlight, in a variety of topics dedicated to sustainable energy sources, as inorganic and organic photovoltaics, photodegradation of pollutants, air cleaning in hospitals, photocatalysis, water cleaning, and bacteria deactivation by singlet oxygen generation. Other topics were associated with fluorescence phenomena, photonic crystals, inorganic nanomaterials for photovoltaics, in particular morphologically different forms of titania, zinc oxide, highly luminescent inorganic and organic nanoparticles, photochemical water splitting, OLEDs, and charge-transfer phenomena. Great attention was dedicated to inorganic nano-materials for environmental protection. There is no doubt that global pollution is a real mess very difficult to deal with everywhere, even in developed countries. Thus, alternative ways to harvest and harness the sunlight into purification of air and portable water are essential for humanity in overcrowded world. Many poster contributions were dedicated to this important topic. The main focus was on titania and titania doped with a variety of other inorganic oxides to enhance its photodegradation power. Several tens of papers dealt with this topic. Several poster contributions were dedicated to spirocompounds and their photochromic properties. Remarkable contribution (again several tens of contributions) were dedicated to solar energy conversion using organic, inorganic, and hybrid photovoltaic materials.

The focus of this conference series is of great importance to the current global energy security situation. A coordinated action on a global level is urgently needed to avert the crisis. The developing world must take an active role in any such coordinated action. Thus, the location of this conference is chosen to engage the scientists and decision makers in the developing world into this action plan. It will be interesting to see how the field has further developed at Solar '10 in 2010.

Mohamed Sabry Abdel-Mottaleb Jean-Marie Herrmann 


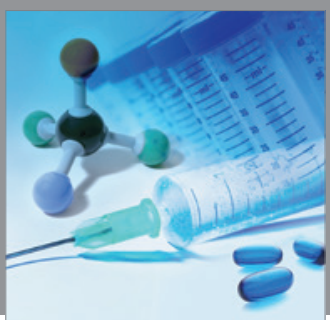

International Journal of

Medicinal Chemistry

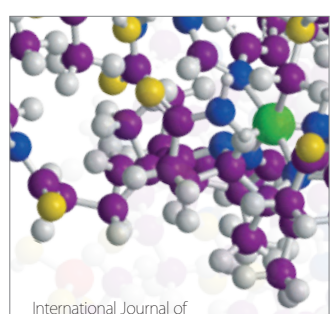

Carbohydrate Chemistry

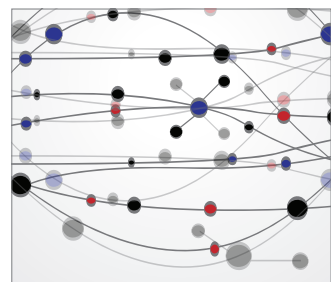

The Scientific World Journal
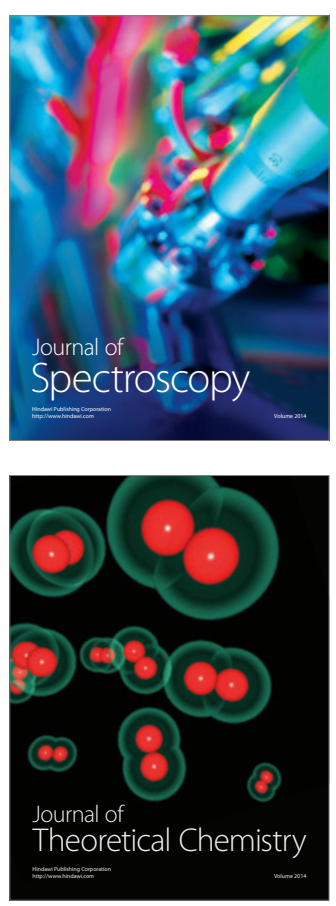
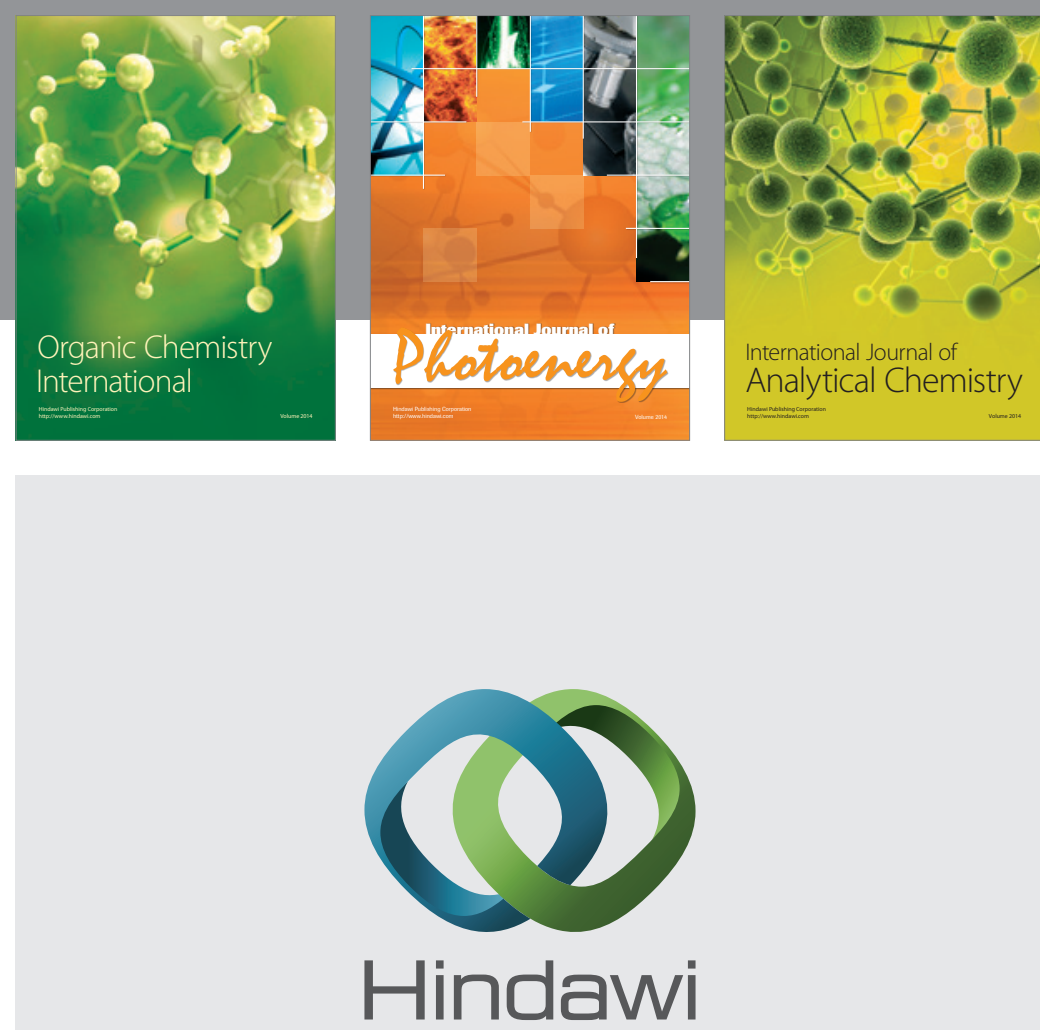

Submit your manuscripts at

http://www.hindawi.com
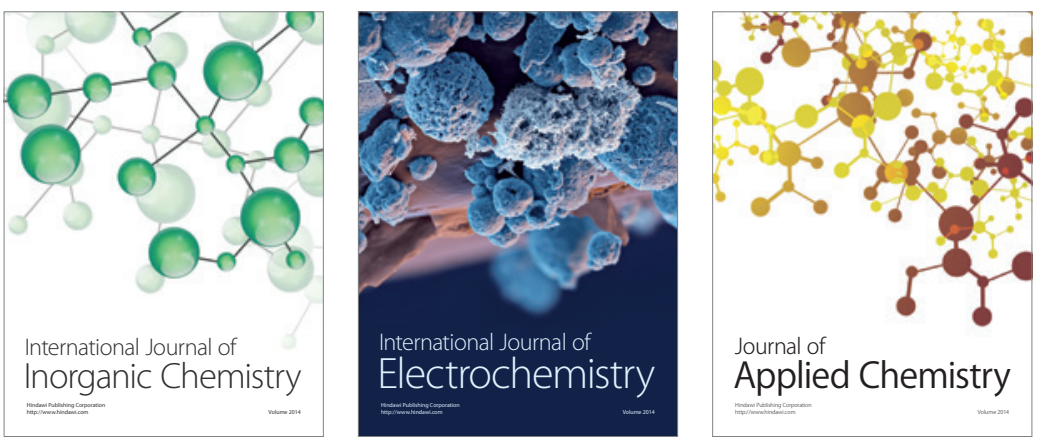

Journal of

Applied Chemistry
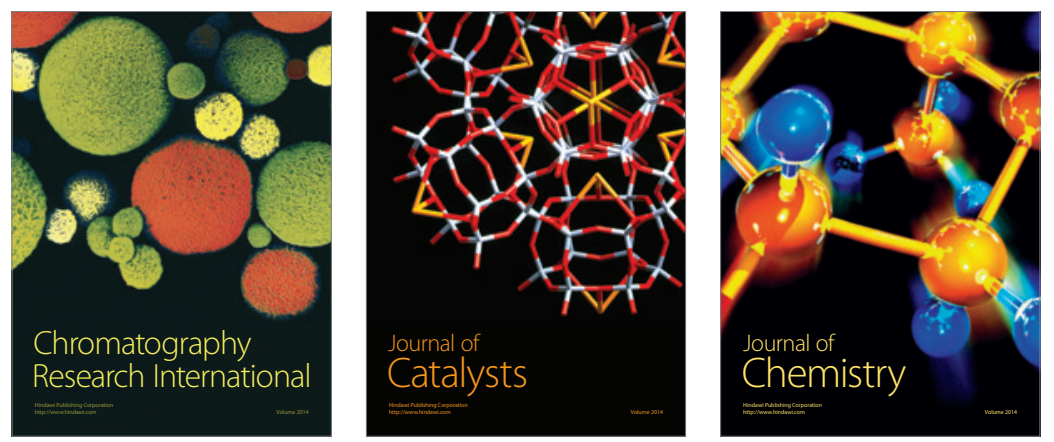
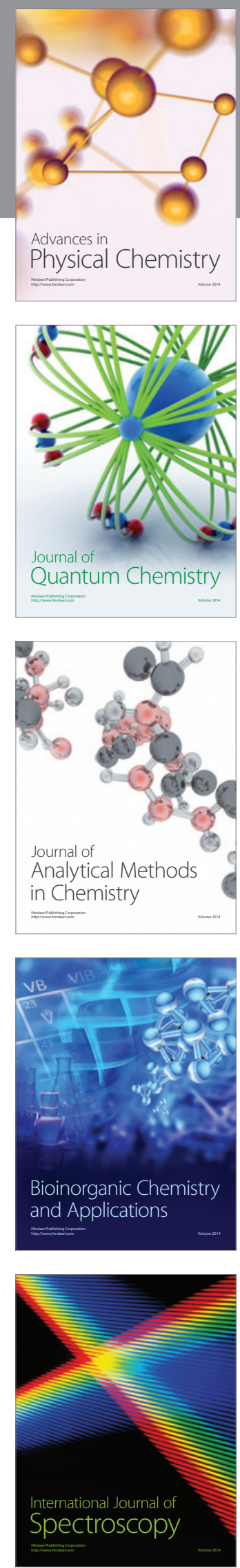